\title{
NUMERICAL INVESTIGATION OF THE POLYMER MELT FLOW IN INJECTION MOLDING BY USING ILU PRECONDITIONED GMRES
}

\author{
U. TÜRK ${ }^{1}$, A. ECDER ${ }^{2} 1$ \\ ${ }^{1}$ Turkish Naval Academy, Technical Sciences Department \\ Tuzla, 81704, Istanbul, Turkey \\ ${ }^{2}$ Department of Mechanical Engineering, Boğaziçi University \\ Bebek, 80815, Istanbul, Turkey \\ E-mail: ${ }^{1}$ otturk@dho.edu.tr, ${ }^{2}$ ecder@boun.edu.tr
}

Received September 30, 1999

\begin{abstract}
The implementation of a modern preconditioned Newton-Krylov solvers to the polymer melt flow in injection molding is the main focus of this paper. The viscoelastic and non-isothermal characteristics of the transient polymer flow is simulated numerically and the highly non-linear problem solved. This non-linear behavior results from the combination of the dominant convective terms and the dependence of the polymer viscosity to the changing temperature and the shear rate. The governing non-Newtonian fluid flow and energy equations with appropriate approximations are discretized by finite differencing. Elliptic Grid Generation technique is used to map physical domain to computational domain. The resulting non-linear system is solved by using Newton's method. GMRES, one of the Krylov subspace methods, used as an iterative algorithm in order to solve the linear system at each non-linear step. Incomplete LU preconditioner is used for better convergence. Numerical solution of polymer flow is presented to demonstrate that these methods are efficient and robust for solving such flow problems.
\end{abstract}

\section{INTRODUCTION}

The focus of current research is to apply the modern numerical methods to the numerical investigation of the polymer melt flow in injection molding. The

\footnotetext{
${ }^{1}$ The work of the first author was supported in part by Turkish Navy. The work of the second author was funded by grant from Boğaziçi University Research Fund, no: 99A602.
} 
code generated in this numerical study of polymer flow, can be used in the design work of various mold shapes. The numerical investigation of such flows is still very challenging due to the temperature and shear rate dependence of the viscosity and the effect of viscosity on the temperature. These effects create the coupling between the stream function equation and the energy equation. The objective of this work is to solve such coupled problem with finite difference discretization, elliptic grid generation technique, and apply the Newton's method to the non-linear problem and at each non-linear step solve the system by using Incomplete LU preconditioned GMRES.

Injection molding method is used in the production of especially the plastics but at the same time composites, ceramics, metals, etc. If the flow and the temperature distribution of the polymer melt in the mold can be modelled numerically, many problems encountered during the production of the mold or the prototype can be anticipated. The numerical modelling before the production eliminates some costs and makes it possible to manufacture more complicated parts.

The recent work on the numerical modelling of the injection molding problems can be summarized as follows. Kamal et al. [1] considered the flow field as a non-isothermal, viscoelastic polymer flow considering the fountain flow at the melt front. Again Kamal et al. [2] simulated the polymer flow with a non-isothermal crystallization model. Hieber and Shen [3] have used a finiteelement/finite difference model for arbitrary mold shapes, but their model neglects the fountain flow and its effects at the melt front.

Subbiah et al. [4] have investigated the mold filling process for a nonisothermal and non-Newtonian polymer with fountain flow effect just on the temperature field. They have used a numerical grid generation method for arbitrary shape molds. The numerical solution of the problem has been achieved by mapping the physical domain to a computational domain. The boundary fitted coordinate system (BFCS) in the physical domain has been generated by Elliptic Grid Generation method.

Kietzmann et al. [12] have developed a free-front tracking algorithm to simulate the filling stage of the injection molding process in a thin gap. They used the finite volume approach and Hele-Shaw flow equations. Smith et al. [13] have computed the fill time and filling pattern for non-linear equations for the polymer melt pressure field which are formed via isothermal Hele-Shaw flow analysis. They used a moving boundary analysis, which is based on the volume-of-fluid (VOF) technique.

The objective of this study is to develop efficient Newton-Krylov solvers for polymer injection flow computations. An approximate system of linear equations arising from the Newton linearization is solved by a Krylov subspace algorithm called Generalized Minimal Residual algorithm. GMRES is a sparse iterative solver for nonsymmetric matrices. In order to improve the convergence properties of the solver a preconditioner must be used. Incomplete LU preconditioner is used for faster convergence of the iterative solver. A remarkable feature of Krylov subspace methods is that the storage of the 
Jacobian matrix can be completely eliminated by approximating the Jacobian with numerical fluxes, resulting in a matrix-free method.

The flow during the injection molding is assumed to be incompressible, viscous, time dependent. The coupling between the momentum and energy equations occurs through viscosity term in both equations.

\section{MATHEMATICAL MODELLING}

In many applications of the injection molding, the item can be thin enough to consider the flow problem in two dimensions. The pressure and the stream function fields can be modeled in two dimensions by using Hele-Shaw approximation [7] for thin walled molds. After the Hele-Shaw approximation, the changes in the $\mathrm{z}$ direction can be eliminated by averaging the velocities along the $\mathrm{z}$ direction. "." indicates the averaged values over the $\mathrm{z}$ direction.

$$
\begin{aligned}
& \bar{u}(x, y)=\frac{1}{h} \int_{0}^{h} u(x, y, z) d z \\
& \bar{v}(x, y)=\frac{1}{h} \int_{0}^{h} v(x, y, z) d z .
\end{aligned}
$$

Injection molding problem requires the solution of the continuity, the momentum and the energy equations. Since the Reynolds number is very small due to the high viscosity of the polymer melt and the slow moving fluid, the inertia terms in the momentum equations can be neglected. The governing equations become;

Continuity equation:

$$
\frac{\partial \bar{u}}{\partial x}+\frac{\partial \bar{v}}{\partial y}=0
$$

X-Momentum equation:

$$
\frac{\partial}{\partial z}\left(\mu \frac{\partial u}{\partial z}\right)-\frac{\partial P}{\partial x}=0
$$

Y-Momentum equation:

$$
\frac{\partial}{\partial z}\left(\mu \frac{\partial v}{\partial z}\right)-\frac{\partial P}{\partial y}=0
$$

Define $S(x, y)$ as the measure of the fluidity,

$$
S(x, y)=\int_{0}^{h} \frac{z^{2}}{\mu} d z
$$


Combine the continuity and momentum equations,

$$
\frac{\partial}{\partial x}\left(S \frac{\partial P}{\partial x}\right)+\frac{\partial}{\partial y}\left(S \frac{\partial P}{\partial y}\right)=0 .
$$

The same can be done for the stream function as well.

$$
\frac{\partial}{\partial x}\left(\frac{1}{S} \frac{\partial \Psi}{\partial x}\right)+\frac{\partial}{\partial y}\left(\frac{1}{S} \frac{\partial \Psi}{\partial y}\right)=0
$$

where

$$
\bar{u}(x, y)=\frac{\partial \Psi}{\partial y}, \quad \bar{v}(x, y)=-\frac{\partial \Psi}{\partial x} .
$$

The solution of the three dimensional energy equation with viscous energy dissipation yields the temperature distribution in the mold. The conduction has to be considered in all three dimensions, but the convective terms are dropped in the direction where the thickness of the mold is very small. The flow front boundary conditions must be stated carefully due to the unknown location and the temperature of the melt front.

Energy equation:

$$
\rho C_{p}\left(\frac{\partial T}{\partial t}+\bar{u} \frac{\partial T}{\partial x}+\bar{v} \frac{\partial T}{\partial y}\right)=k\left(\frac{\partial^{2} T}{\partial x^{2}}+\frac{\partial^{2} T}{\partial y^{2}}+\frac{\partial^{2} T}{\partial z^{2}}\right)+\mu \dot{\gamma}^{2} .
$$

The shear rate in squared form is given as follows:

$$
\dot{\gamma}^{2}=\left(\frac{\partial u}{\partial z}\right)^{2}+\left(\frac{\partial v}{\partial z}\right)^{2} .
$$

The viscosity is highly dependent on the temperature and the shear rate. The velocities from the solution of the flow field are involved in the solution of the energy equation. With these contributions, the solution of the coupled equations requires non-linear solution methods.

\subsection{Boundary Conditions}

The boundary conditions for Hele-Shaw flow are given as follows:

$$
\{u\}_{z=h}=\{v\}_{z=h}=0 ; \quad\left\{\frac{\partial u}{\partial z}\right\}_{z=0}=\left\{\frac{\partial v}{\partial z}\right\}_{z=0}=0 .
$$

The walls are kept at a certain temperature and the inlet temperature has to be stated as well. The symmetry condition for the temperature causes the change in the temperature at the midpoint of the gaplength to be zero. 


$$
\left\{\frac{\partial T}{\partial z}\right\}_{z=0}=0 ; \quad T=T_{\text {inlet }} \quad \text { at the inlet; } T=T_{\text {wall }} \quad \text { at the walls. }
$$

The temperature of the all free surface nodes are taken equal to the temperature of the central node just behind the free surface. With this method Subbiah et al. [4] introduced the fountain flow effect to the solution.

\subsection{Boundary Conditions for the Stream Function and Pressure}

The pressure is kept constant at the inlet and set equal to zero at the flow front. On the other hand the difference of the stream function between the mold walls is set equal to the flow rate of the melt at the inlet. The Hele-Shaw approximation states the velocities at the top and the bottom walls to be zero while, stream function formulation causes slip condition at the side walls.

$$
\begin{gathered}
P_{\text {inlet }, \text { free surface }}=\text { constant } ; \quad \frac{\partial P}{\partial n} \text { mold walls } \\
=0, \\
\Psi_{\text {mold walls }=\text { constant } ; \quad \frac{\partial \Psi}{\partial n}_{\text {inlet },} \quad \text { free surface }}=0 .
\end{gathered}
$$

\subsection{Viscosity Modelling}

The non-Newtonian characteristics of the polymer melt has to be considered. The viscosity have to be investigated in three dimensions. The viscosity is highly dependent on the temperature and the shear rate. There are different models to predict the viscosity of the polymers. In this study Carreau model [8] implemented. The temperature dependence is introduced by an Arrhenius type of term [6].

$$
\mu=\left\{\mu_{\infty}+\left(\mu_{0}-\mu_{\infty}\right)\left(1+\lambda^{2} \dot{\gamma}^{2}\right)^{\left[\frac{n-1}{2}\right]}\right\} \exp \left\{-\frac{A_{n}\left(T-T_{0}\right)}{T_{0}}\right\}
$$

\section{COMPUTATIONAL MODELLING}

\subsection{Numerical Methods}

Computational Fluid Dynamics (CFD), with its increasing importance, is an area, where the solution methods for engineering problems are developed with the use of computers. In the recent decades, there have been numerous developments in CFD methods as well as in the computers. The main purpose of this study is to utilize the modern methods in CFD, to solve the non-linear governing equations arising from the injection molding problem. 
The use of robust algorithms with Newton's method to solve various problems of interest is growing in popularity mainly due to the rapid progress in computer speed and available memory and advances in iterative solution methods. Newton's method is a robust technique which converges rapidly for non-linear problems if the initial guess is close to the solution. In injection molding problem, the discretization of flow field (stream function, pressure) and energy equations, results in coupled non-linear systems of equations, which can be solved by Newton's method.

At each Newton step, a linear problem is solved to determine the Newton update, $\delta x$. The linear systems at each Newton step results in

$$
J \delta x=-F(x),
$$

where $J$ is the Jacobian matrix and $F$ is the vector of discrete governing equations (right hand side vector). Krylov subspace methods try to find approximations to $\delta x$.

At each non-linear step of Newton's method, an iterative solver is used to solve the linear system. Krylov subspace methods are fast iterative methods to solve a system of linear equations. The use of Krylov subspace methods in conjunction with the Newton's method, are simply called Newton-Krylov methods.

A striking advantage of iterative methods like Krylov subspace methods is the reduced memory requirements (compared to the factorization based methods, like Gaussian elimination). On the other hand, it is possible to start iterations with a relaxed tolerance and decrease the magnitude of the tolerance with increasing iteration number, while the convergence takes place. [10]

One such Krylov technique is the Generalized Minimal Residual (GMRES). In this study, at each step of Newton's method, the system of linear equations is solved by GMRES. GMRES does not require the Jacobian to be symmetric and/or positive definite. GMRES minimizes the norm of the computed residual vector at every step over a Krylov subspace, which contains a certain number of orthogonal search directions. The algorithm is derived from the Arnoldi process for constructing an $I_{2}$-orthogonal basis of Krylov subspaces. [5]

Using GMRES, the norm of the residual is non-increasing, and the norm can be monitored without constructing intermediate iterates. The eigenvalues are approximately given at no extra cost, for spectral analysis, that enables convergence studies.

The cost of allowing the Jacobian to be non-symmetric in Krylov methods is that the current iterate depends on all previous iterates that causes operation count and storage requirements to grow quadratically and linearly, respectively, in the iteration index. To overcome this problem one can restart the algorithm periodically or restrict the orthogonalization process to a moving window of the most recent iterates. Both of these variences with bounded recurrence relation suffer the loss of finite termination property. Instead of 
restarting the algorithm, convergence can be improved by preconditioning techniques.

In Krylov algorithms, the Jacobian is required only in the form of matrixvector products, referred as the 'matrix-free' implementation. The product can be approximated by finite differences. The storage of the Jacobian matrix can be eliminated by matrix free implementation. However, the Jacobian is needed periodically during the outer Newton iteration to generate an effective preconditioner for the inner Krylov iteration.

$$
J w \approx \frac{F(x+\varepsilon w)-F(x)}{\varepsilon} .
$$

The condition number of the system matrix plays a major role in the convergence rate of the iterative solver. The iterative solvers perform better with the linear systems, for which the eigenvalues of the system matrix are clustered. The method, called the preconditioning, attempts to change the linear system to another one, which has the same solution, but with eigenvalues clustered at a single value. Preconditioning, (2.1) accelerates the convergence of the linear system, which means, the decrease in computation time and effort; (2.2) decreases the number of time steps to reach a steady state solution. [11]

Left preconditioning involves premultiplying the linear system $A x=b$; with a matrix as $P^{-1} A x=P^{-1} b$ where $P$ is preconditioning matrix. The best preconditioning matrix for $A$ would cluster as many eigenvalues as possible at unity. Obviously, the optimal choice of $P$ is $A$, in which case the underlying matrix problem for GMRES is trivially solved with one Krylov vector. Preconditioning will be cost effective only if the additional computational work incurred for each subiteration is compensated for by a reduction in the total number of iterations to converge. In this way, the total cost of solving the overall non-linear system is reduced. [11]

ILU (Incomplete LU) preconditioner is employed for better spectral properties of the system matrix.

\subsection{Numerical Grid Generation}

In order to enhance the efficiency and accuracy of the numerical scheme and to simplify the implementation of boundary conditions, a transformation from physical space $(x, y, z)$ of the polymer melt in the mold to computational space $(\xi, \eta, z)$ is performed. Boundary Fitted rectangular type grid is generated by the use of an elliptic grid generation code. The governing equations are transformed to the computational domain as well. The finite differencing is employed to discretize the partial differential equations in computational domain.

In the elliptic grid generation method, a set of differential equations has to be solved by finite difference technique.

$$
\alpha x_{\xi \xi}-2 \beta x_{\xi \eta}+\gamma x_{\eta \eta}=-I\left(P x_{\xi}+Q x_{\eta}\right),
$$




$$
\alpha y_{\xi \xi}-2 \beta y_{\xi \eta}+\gamma y_{\eta \eta}=-I\left(P y_{\xi}+Q y_{\eta}\right)
$$

where $\alpha=x_{\eta}^{2}+y_{\eta}^{2} ; \gamma=x_{\xi}^{2}+y_{\xi}^{2} ; \beta=x_{\eta} x_{\xi}+y_{\eta} y_{\xi} ; I=x_{\xi} y_{\eta}-y_{\xi} x_{\eta}$.

The Jacobian is,

$$
\begin{gathered}
J=\frac{1}{I}=\frac{1}{x_{\xi} y_{\eta}-y_{\xi} x_{\eta}} \\
\xi_{x}=I y_{\eta} \quad \xi_{y}=-I x_{\eta} \quad \eta_{x}=-I y_{\xi} \quad \eta_{y}=I x_{\xi} .
\end{gathered}
$$

$P$ and $Q$ are the grid control functions. It is possible to increase the number of grid points at certain areas of the physical domain by changing $P$ and $Q$. In this study, $P$ and $Q$ are set equal to zero, which creates a uniform mesh. The transformation equations and the transformed form of the governing equations can be seen in Erol's thesis work [9].

\section{RESULTS}

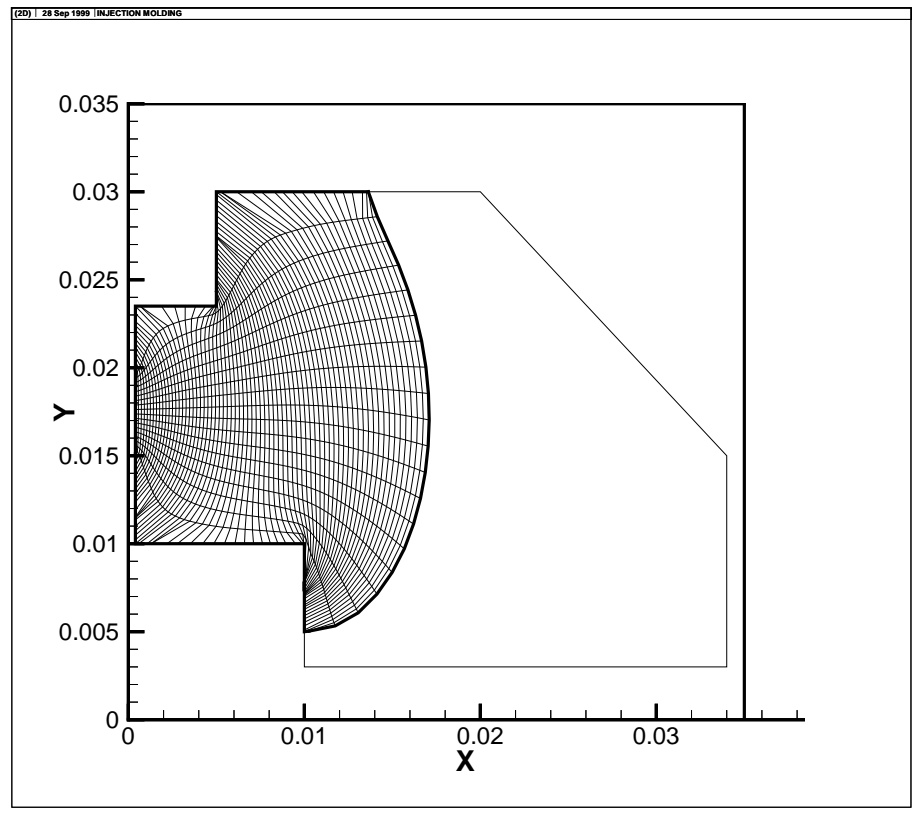

Figure 1. Mold Filling Process.

A computer code has been developed which uses Newton-Krylov methods, preconditioning and elliptic grid generation methods. As a model problem, the 


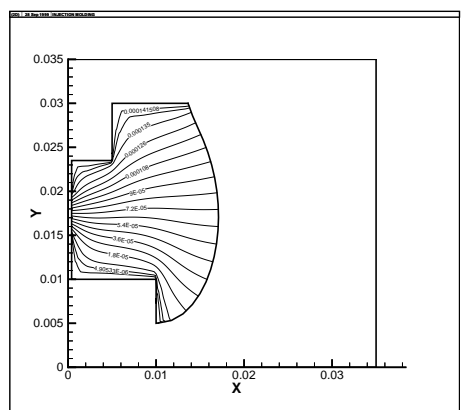

a)

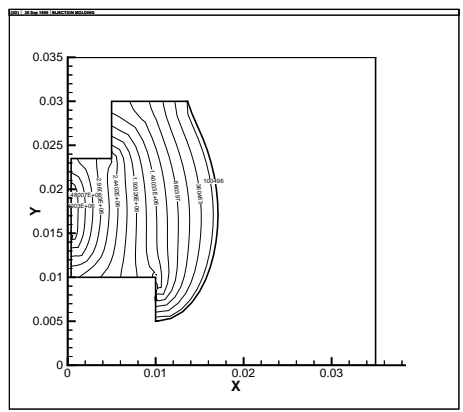

b)

Figure 2. a. Stream Lines b. Pressure Contours in Mold Filling Process.

viscous flow of polymer melt in an arbitrary shape mold is investigated. The inlet temperature and pressure kept constant as well as the wall temperatures. The code includes the subroutines which solve the coupled non-linear systems for the stream function, the pressure and the temperature fields. Another subroutine provides the solution of elliptic grid generation. This coupled, highly non-linear problem can be solved by iterative sparse matrix solution methods and the finite difference discretization tools.

The numerical experiments show that Newton-Krylov methods accelerate the solution of non-linear injection molding problem. In Newton's method when the initial guess is a good approximation of the solution, the convergence is faster. Each time step requires the solution of the non-linear problem with unknown velocity, temperature, and viscosity distributions. It is possible to feed the values at the previous step as the initial values to the system at the current step. This advantage of the method and problem is disappeared, every time a new line of nodes added to the flow front. At such step, the convergence requires more iterations, due to the slight changes in initial conditions for Newton's method.

The tests conducted for the same problem without a preconditioner and with ILU preconditioner have proven that an efficient preconditioner is required for Krylov subspace methods. The numerical experiments, whose results are shown in Figures 1 and 2, are conducted by use of ILU preconditioner. When the preconditioner is removed with the same computer and the same mesh size, it is impossible to get satisfactory results in a reasonable period of time.

The use of GMRES is proven to be a good choice as an iterative solver. It is possible to solve large systems by GMRES at each Newton's step.

The grid size is constant in the y direction and 20 , but in the $\mathrm{x}$ direction with the advancing flow front grid size increases up to 120. In Figure 1, the physical mesh can be seen. Figure 2 shows the stream lines and pressure contours respectively in (a) and (b).

The model problem has also been tested for simple mold shapes, where 
analytical solutions are possible. It has been observed that the results are in good agreement.

It has been also observed that the experiments conducted by Erol [9] and the results of this work are also in good agreement. Erol has taken some pictures during the experiments and the comparison of these pictures with the generated computer plots show that the flow front is similar to what has been expected.

\section{CONCLUSIONS}

The flow and temperature fields of the melt polymer in injection molding simulated. Both fields are coupled through the viscosity, temperature, and shear rate dependence. The injection molding into thin walled cavity is simulated by using modern CFD techniques and the results are presented.

In the numerical experiments, Newton-Krylov methods are proven to be extremely effective for numerical solution of non-linear problem of polymer melt flow. Among other preconditioners, ILU preconditioner is used to improve spectral properties of linear systems at each Newton's step. It has been seen that Krylov iterative solver, GMRES, performs better with an efficient preconditioner.

The code generated can be a tool to analyze the flow of polymer melt in the thin walled molds.

\section{REFERENCES}

[1] M. R. Kamal, E. Chu, P. G. Lafleur and M. E. R. Yan. Computer Simulation of Injection Mold Filling for Viscoelastic Melts with Fountain Flow. Polym. Engng., 26 (3), 1986, $190-196$.

[2] M.R. Kamal, S.K. Goyal and E. Chu. Simulation of Injection Mold Filling of Viscoelastic Melts with Fountain Flow. A.I.Ch.E.Jl., 34 (1), 1988, $94-106$.

[3] C.A. Hieber and S.F. Shen. A Finite-Element/Finite Difference Simulation of the Injection Molding Filling Process. J. Non-Newtonian Fluid Mech., 7 (1), 1980, 1 - 32.

[4] S. Subbiah, D. L. Trafford and S. I. Güçeri. Non-Isothermal Flow of Polymers into TwoDimensional, Thin Cavity Molds: A Numerical Grid Generation Approach. Int. J. Heat Mass Transfer, 32 (3), 1989, 415 - 434.

[5] Y. Saad and M.H. Schultz. GMRES: A General Minimal Residual Algorithm for Solving Nonsymmetric Linear Systems. SIAM Journal of Sci. Stat. Comput., 7 (3), July 1986, $856-869$.

[6] R.B. Bird, R.C. Armstrong and O. Hassager. Dynamics of Polymer Liquids. Vol.1, Wiley, New York, 1977, p.235.

[7] H. Schlichting. Boundary Layer Theory. McGraw-Hill, New York, 1968.

[8] P.J. Carreau. Ph. D. Thesis. University of Wisconsin, Madison, 1968.

[9] A. Erol. MS Thesis. Boğaziçi University, Istanbul, 1998.

[10] P.R. McHugh and D.A. Knoll. Comparison of Standard and Matrix-Free Implementations of Several Newton-Krylov Solvers. AIA A Journal, 32 (12), December 1994, 2394 -2400 . 
[11] H. Luo, J.D. Baum, and R.Lohner. A Fast Matrix-free Implicit Method for Compressible Flows on Unstructured Grids. Journal of Computational Physics, 146, 1998, 664 -690 .

[12] C.V.L. Kietzmann, J. P. Van der Walt and Y. S. Morsi. A Free-Front Tracking Algorithm for A Control-Volume-Based Hele-Shaw Method. Int. J. for Num. Methods in Engineering, 41 (2), 1998, 253 - 269.

[13] D.E. Smith, D. A. Tortorelli and C. L. Tucker III. Analysis and Sensitivity Analysis for Polymer Injection and Compression Molding. Comput. Methods Appl. Mech. Engrg., 167 (3-4), 1998, 325 - 344.

\section{POLIMERINIO LYDINIO TEKĖJIMO SKAITINE் ANALIZE் PANAUDOJANT GMRES METODĄ SU ILU SĄLYGOTUMĄ GERINANČIA MATRICA}

U. TURK, A. ECDER

Šiame darbe nagrinëjamas šiuolaikinių Niutono-Krylovo metodų efektyvumas, kai jais sprendžiame polimerinio lydinio tekèjimo uždavinį. Uždavinys yra stipriai netiesinis, tai sąlygoja vyraujančiu konvekcinių narių sąveika ir koeficientų priklausomybè nuo temperatūros. Uždavinys aproksimuojamas baigtiniu skirtumų schema. Panaudojant elipsini tinklo generatorių fizinè skaičiavimo sritis yra atvaizduojama ic skaičiavimo sritį. Gautoji netiesinių lygčiu sistema sprendžiama Niutono metodu. Kiekviename iteraciniame žingsnyje tiesinių lygčių sistema sprendžiama GMRES metodu, kuris modifikuojamas nepilnos LU faktorizacijos neišreikštiniu operatoriumi. Pateiktieji skaičiavimo eksperimento rezultatai iliustruoja algoritmų efektyvumą ir universalumą. 